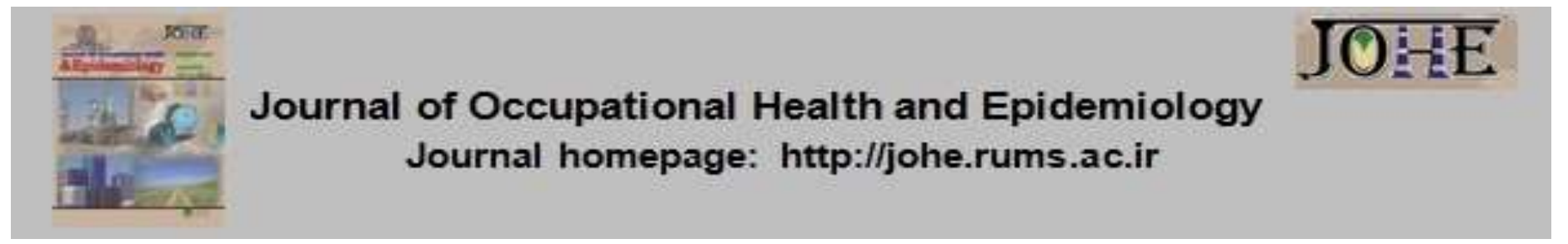

\title{
Association between Social Capital with Occupational Stress and Burnout among the Staff of Rafsanjan University of Medical Sciences in 2016
}

\author{
Hossein Sajadian ${ }^{1}$, Seyed Habiballah Hosseini², Maryam Tajadini ${ }^{3}$, Ali Akbari ${ }^{*}$ \\ 1-MSc in Psychology, School of Nursing and Midwifery, Rafsanjan University of Medical Sciences, Rafsanjan, Iran. \\ 2- Assistant Prof, Dept. of Nursing Management, School of Nursing and Midwifery Geriatric Care Research Center, Rafsanjan, \\ University of Medical Sciences, Rafsanjan, Iran. \\ 3- Instructor, Dept of Anesthesiology, Paramedical Faculty, Rafsanjan University of Medical Sciences, Rafsanjan, Iran. \\ 4- Instructor, Dept of Medical Surgical Nursing, School of Nursing and Midwifery Social Determinants of Health Research Center, \\ Rafsanjan University of Medical Sciences, Rafsanjan, Iran.
}

\section{Article Info}

* Corresponding author:

Ali Akbari,

E-mail:

iccn87@gmail.com

\section{Article history}

Received: Aug 2020

Accepted: Dec 2020

10.29252/johe.9.3.167

Print ISSN: 2251-8096 Online ISSN: 2252-0902

Peer review under responsibility of Journal of Occupational Health and Epidemiology
Citation: Sajadian H, Hosseini SH, Tajadini M, Akbari A. Association between Social Capital with Occupational Stress and Burnout among the Staff of Rafsanjan University of Medical Sciences in 2016. JOHE 2020; 9(3):167-72.

Keywords: Social Capital, Occupational Stress, Occupational Burnout, Staff.

\section{Introduction}

The spread and speed of scientific achievements and breakthroughs, as well as the skills resulting from them, are associated with numerous social and economic developments, changing humans life and occupation. Given the complex nature of humans as living creatures, there are numerous differences in their adaptation to the environment, attempts to fulfill their needs, and cope with the equipment and changes in the workplace. In the present century, humans have to bear limits and pressures while trying to adapt to their social and occupational environments [1].

One of the most significant factors associated with occupation, especially in difficult ones, is occupational burnout. Occupational burnout is one of the psychological signs commonly observed in jobs with many hours of communication with humans [2]. 
It is currently a common problem in all health systems. According to the statistics, one out seven employees suffer from occupational burnout. The United States Intelligence Office indicates that, among all jobs, the health-related ones suffer from the highest level of occupational damages, including occupational burnout syndrome [3].

Occupational burnout refers to a delayed response to chronic emotional and interpersonal stressful factors in jobs [4]. Indeed, in the modern world, there are numerous mental tensions, some of which are occupation-specific. These tensions are likely to bring about dissatisfaction with occupations, thus occupational burnout [5]. The studies have indicated that stress and tension with different levels are the inevitable parts of every job [6]. Given their duties for providing patients with health and treatment, the healthcare staff are under numerous stressful factors. These long-term and continuous stressful factors result in occupational burnout. As a physical-mental syndrome, it is likely to lead to problems such as resignation, repeated absences, reduced energy, and decreased efficiency in these individuals [7]. Occupational environments, such as surgery rooms, burn wards, and psychiatry wards, can have remarkable effects on the personnel's mental health status [8]. Occupational stress has significant effects on organizational inadequacy, increased employee movement, absence from work due to illnesses, reduced healthcare quality and quantity, increased healthcare and medical costs, and reduced occupational satisfaction [9, 10].

Occupational burnout can also affect some other factors, one of which is social capital. Social capital is a multi-dimensional concept in social studies affecting numerous psychological domains. It is defined as social life, networks, norms, trust that give the participants the power to conduct common goals more effectively [5].

Social capital is the legacy of social relations, facilitating social activities. It includes social trust, participatory norms, and relation networks. Moreover, it can bring individuals together, in a coherent and stable way, to achieve a common goal [11]. Various factors are related to occupational stress and burnout in medical staff, one of which is social capital. People or managers who establish social capital in the organization can smooth the path to their professional and organizational success. The researchers have indicated that social capital has a significant negative relationship with occupational burnout [12-14]. In a study on the relationship between employment-based social capital, job stress, burnout, and intent to leave among child protection workers, Boyas et al. (2012) have concluded that social capital has a significant negative relationship with job stress, burnout, and intent to leave [12]. Moreover, in another study on the relationship between social capital and occupational stress, Sepahvandi et al. (2014) conclude that social capital has a significant negative relationship with occupational burnout [14]. On the other hand, the results of Janssens's study show no relation between social capital and occupational burnout [15].

Given their duties for providing patients with health and treatment, the healthcare staff are under stress and occupational burnout more than any other occupational group. One of the factors playing an important role in achieving the goals defined by organizations is the existence of informal groups and the relations ruling them in such organizations, reducing stress significantly. Social capital investigates these informal relations in the workplace. To the best of the authors' knowledge, no study has shown a cumulative relationship of social capital with occupational stress and burnout. The present study aims to investigate the effect of social capital (including seven components of trust, networks, cooperation, relations, values, mutual understanding, and commitment) on occupational stress and burnout among the staff of the Azad University of Sirjan.

\section{Materials and Methods}

In the present descriptive-correlational study, the staff of Rafsanjan University of Medical Sciences (working in the academic year 2015-2016) was the statistical population. At first, the project was confirmed at the research council of the Azad University of Sirjan. The researcher then conducted the sampling process.

To determine the required sample size at a confidence level of $95 \%$, a correlation coefficient of 0.68, and possible accuracy 0.1, after quantification in the statistical formula, the sample size was estimated to be approximately 156 people [16].

The inclusion criteria included having at least one year of work experience, working at the medical health centers affiliated with Rafsanjan University of Medical Sciences (when the study was being conducted), and providing a written letter of consent for entering into the study. The exclusion criterion of this study was suffering from mental/psychological diseases.

Then, the questionnaires were distributed with a simple random method; each of the 3254 employees was assigned a number between 1 and 3254, after which 156 numbers were chosen at 
random. The goals of the study were explained to the participants, they were assured about the confidentiality of their information, and, finally, they provided their written consent to participate in the project. The participants were then provided with the questionnaires.

The data collection tools included a) demographic information questionnaire, b) the twenty-eight-item social capital questionnaire of Vilanova and Chosa (2003), c) The thirty-five-item occupational stress questionnaire (provided by Health and Safety Executive (HSE) and translated by Esfandiar Azad, with confirmed validity and reliability ), and d) the twenty-two-item occupational burnout questionnaire (Maslach, 1981); it was based on a new assessment of tension, i.e., burnout. The score of these tools was obtained by adding the score of the items and averaging them.

After collecting the data, they were analyzed using
SPSS-20. The data analysis of the questionnaires was conducted at two levels, i.e., descriptive and inferential statistics. At the former level, the researchers applied frequency, percentage, mean, standard deviation, and variance. At the latter level, they used Pearson's Correlation Coefficient and regression. The significance level was determined to be 0.05 .

\section{Results}

The present research results indicated that the mean age of participants was $35.78 \pm 10.57$ years; further, the minimum age was 18 , and the maximum was 61 . Moreover, the results indicated that most of the participants were women, married, and a work experience of more than 16 years. In addition, most of the participants had the educational level of bachelor (Table 1).

Table 1. The frequency distribution and demographic characteristics percentage

\begin{tabular}{|c|c|c|c|}
\hline \multicolumn{2}{|c|}{ Variable } & \multirow{2}{*}{$\begin{array}{c}\text { Frequency } \\
74\end{array}$} & \multirow{2}{*}{$\frac{\text { Percentage }}{47.4}$} \\
\hline Gender & Men & & \\
\hline & Women & 82 & 52.6 \\
\hline \multirow[t]{4}{*}{ Work experience } & $1-5$ years & 42 & 26.9 \\
\hline & $6-10$ years & 41 & 26.3 \\
\hline & $11-15$ years & 20 & 12.8 \\
\hline & More than 16 years & 53 & 34.0 \\
\hline \multirow[t]{2}{*}{ Marital status } & Single & 32 & 20.5 \\
\hline & Married & 124 & 79.5 \\
\hline \multirow[t]{4}{*}{ Educational level } & High school diploma & 33 & 21.2 \\
\hline & Associate degree & 42 & 26.9 \\
\hline & Bachelor & 53 & 34 \\
\hline & Master and higher & 28 & 17.9 \\
\hline
\end{tabular}

Based on the information provided in Table 2, social capital has a significant relationship with occupational stress and burnout at the significance level of 0.01 ; the significance level is smaller than 0.01 . Moreover, this value is -0.70 for the relationship between social capital and occupational stress and -0.78 for the relationship between social capital and occupational burnout. Thus, the more the occupational stress and burnout, the less the social capital of the staff working in Rafsanjan University of Medical Sciences and vice versa.

Table 2 lists the results for the demographic characteristics. The model identified that there was no link between social capital, occupational stress, occupational burnout with demographic characteristics. But there is an exception; significant relationship between work experience and occupational burnout.

Table 2. Relationship between demographic profile and social capital, occupational stress, and occupational burnout

\begin{tabular}{ccccccc}
\hline \multirow{2}{*}{ Variable } & \multicolumn{2}{c}{ Social capital } & \multicolumn{2}{c}{ Occupational stress } & \multicolumn{2}{c}{ Occupational burnout } \\
\cline { 2 - 7 } & $\begin{array}{c}\text { Regression } \\
\text { coefficient }\end{array}$ & $\begin{array}{c}\mathbf{p}- \\
\text { value }\end{array}$ & $\begin{array}{c}\text { Regression } \\
\text { coefficient }\end{array}$ & $\begin{array}{c}\mathbf{p}- \\
\text { value }\end{array}$ & $\begin{array}{c}\text { Regression } \\
\text { coefficient }\end{array}$ & p-value \\
\hline Gender & 0.031 & 0.21 & 0.017 & 0.09 & 0.003 & 0.97 \\
\hline Work experience & 0.072 & 0.319 & 0.167 & 0.302 & 0.002 & 0.001 \\
\hline Marital status & -0.002 & 0.10 & -0.054 & 0.102 & 0.027 & 0.33 \\
\hline Educational level & 0.006 & 0.07 & -0.003 & 0.06 & -0.031 & 0.45 \\
\hline
\end{tabular}


Based on the information given in Table 3, a significant negative relationship was observed between social capital and occupational stress at the level of 0.01 . Moreover, this value for the relationship between occupational stress with social trust, networks, cooperation, relations, values, mutual understanding, and commitment was $-0.72,-0.56,-0.52,-0.58,-0.68,-0.73$, and 0.74 , respectively. Thus, the more the occupational stress, the less the social capital of the staff working in Rafsanjan University of Medical Sciences and vice versa.

Table 3. Pearson's Correlation Coefficient for the relationship between social capital aspects, occupational stress, and occupational burnout

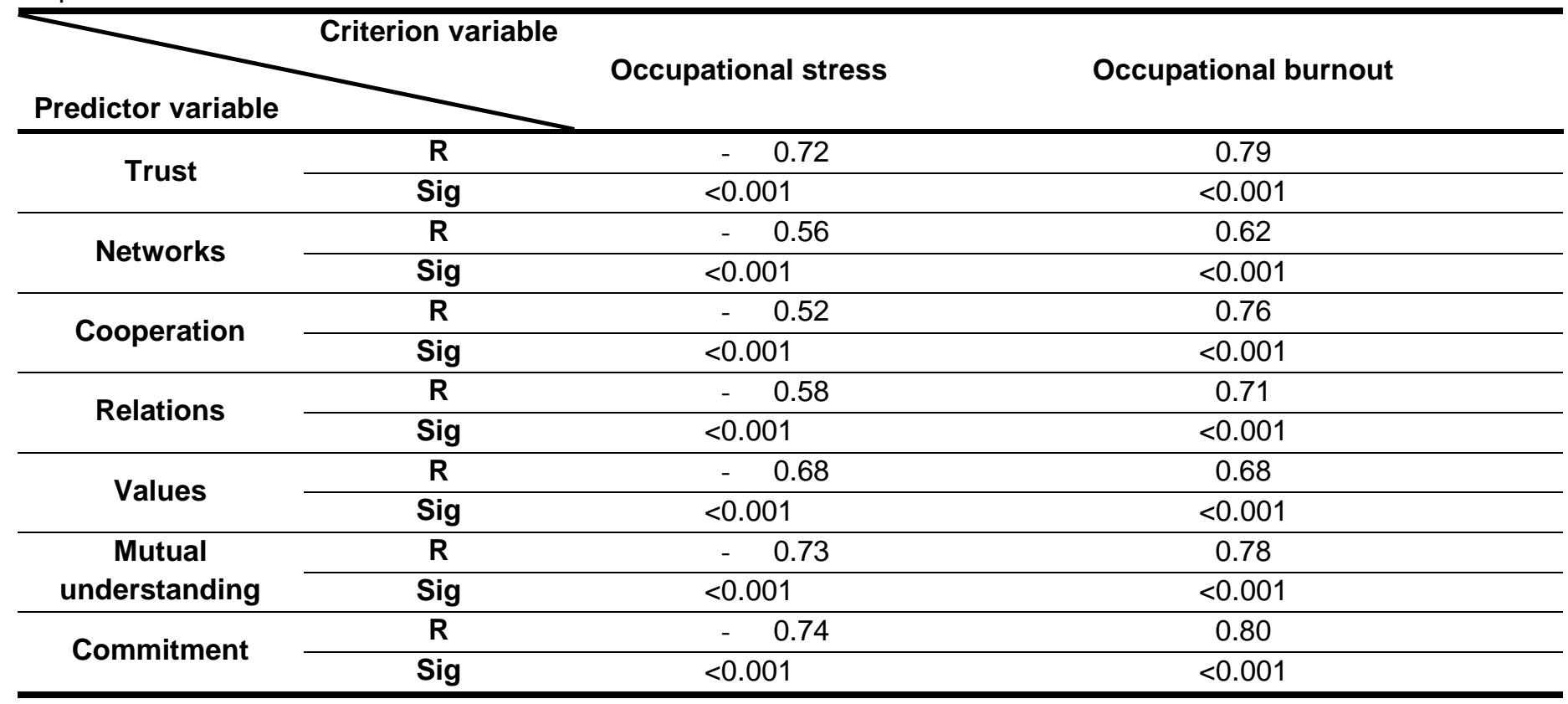

R: Correlation coefficient

Sig: $p$-value

According to Table 4, a significant negative relationship was observed between social capital and occupational burnout at the level of 0.01 ; the significance level is smaller than 0.01 . Thus, the more occupational burnout, the less the social capital of the staff working in Rafsanjan University of Medical Sciences and vice versa.

\section{Discussion}

The present study was conducted to investigate the relationship between social capital and occupational stress and burnout among the staff of Rafsanjan University of Medical Sciences. The analysis of the results is provided in the following paragraphs, and some suggestions are given as well.

The results of the present study indicated that the more occupational burnout, the less the social capital of the staff. These results were in line with those of studies conducted by Griffin et al. (2010), Driller et al. (2011), Sepahvandi et al. (2014), and Bar Abadi et al. (2015) [14,17,18,19]. However, the results of Janssens's study showed no relation between social capital and occupational burnout [15].

In explaining these results, it can be stated that social capital is the legacy of social relations, facilitating social activities. Social capital includes trust, participatory norms, and social relation networks. Moreover, it can bring individuals together, in a coherent and stable way, to achieve a common goal. This results in an increased level of health, efficiency, and usefulness, ultimately reducing occupational burnout [11]. Furthermore, social capital is the sum of real or potential sources resulting from enduring networks of almost institutionalized relations in groups. A network that provides all of its members with collective capital supports, which ensures them not to suffer from tension, resulting in reduced occupational burnout [20].

Moreover, the present study results indicated that the more the occupational stress, the less the social capital of the staff and vice versa. The findings of this section were in line with those of Gächter et al. (2011) and Boyas et al. (2010) [21, 22]. Some studies did not consider the relationship between social capital and occupational stress [23].

In explaining these results, it can be said that occupational stress results in risky behaviors and social damages; this threatens the health of people, staff, and managers, endangering their income and social capital. 
Furthermore, the present study indicated that occupational burnout could predict nearly $60 \%$ of social capital changes and with each unit change in occupational burnout, the social capital of the staff of Rafsanjan University of Medical Sciences changed as well, i.e., they were reduced. The findings of this section were in line with those of the studies conducted by Driller et al. (2011), Sepahvandi et al. (2014), and Lambert et al. (2010) [14, 18, 23].

Further, it was shown that when the occupational stress of the staff of Rafsanjan University of Medical Sciences increased, the social capitals reduced. This result was in line with that of the studies conducted by Shalani et al. (2020), Gächter et al. (2011), and Boyas et al. (2010) [13, 24, 25].

In explaining these findings, it can be stated that long-term and continuous stressful factors result in occupational-physical reactions. As a physicalmental syndrome, occupational burnout is likely to lead to problems such as resignation, repeated absences, reduced energy, and decreased efficiency in individuals. This is possibly owing to the nature and quality of work in these centers; the healthcare staff deal with humans' life and death, as well as health and recovery. These issues are stressful in nature, making serious problems for nurses, thus affecting the quality of their life and health. Social capital can play an important role in reducing the stress experienced by the healthcare staff by increasing the level of hope, having the required confidence to challenge problems, insisting on goals, and changing the directions and guidelines for achieving the goals (whenever it is deemed as necessary) [25].

One limitation of this study is that it has been conducted with staff from limited organizations. The organizations do not represent all mental states and organizational contexts, diminishing generalizability. The findings provide some evidence to suggest that employment-based social capital is a helpful explanatory dynamic for assessing the quality of relationships in the workplace and how they might be used to safeguard against job stress and burnout.

One of other limitations of the present project was the unwillingness of the individuals to participate. Although participating in the study was voluntary, it was attempted to obtain the individuals' consent for participation by explaining the project goals. Since the data were collected in one city, precaution must be taken in generalizing the results to other areas and cities.

\section{Conclusion}

The present study results indicate that social capital has a significant negative relationship with occupational stress and burnout. It can be stated that social capital growth in the organization improves indirect job stress and burnout. Occupational stress and burnout can predict the social capital of the staff working for Rafsanjan University of Medical Sciences. In other words, a high level of social capital is likely to result in increased occupational satisfaction and reduced occupational stress. Since some of the stressful factors are inevitable in every job and it is required to prevent the stress-related mental and behavioral effects on the staff, the managers of healthcare organizations are supposed to take measures for improving the workplace conditions. Besides, facilitating social communications among the personnel is a secure way to strengthen social capital. The precondition for developing these communications is creating a proper social atmosphere.

\section{Acknowledgement}

The authors express their sincere gratitude to all of the staff working for Rafsanjan University of Medical Sciences for their sincere cooperation in the present study. Moreover, the authors express their sincere thanks to the authorities in charge and the vice-chancellor for research at the Azad University of Sirjan for the financial support provided. This article has been extracted from the Master Thesis with the 94058 plan code.

Conflict of interest: None declared.

\section{References}

1. Afshani A, Jahanbakhshganjeh $S$, Jahanbakhshganjeh $S$. The role of organizational commitment, social support, general health and job satisfaction in predicting burnout among the staff of Social security organization at Kohgiluyeh and Boyer Ahmad. Knowledge \& Research in Applied Psychology 2017; 18(2):72-81.

2. Khammarnia M, Tourani S, Mohammadi R. The effect of social capital dimensions on burnout in female nurses. Hormozgan Medical Journal 2011; 15(3):e88487.

3. Arab M, Rahimi A, Vali L, Ravangard R, Akbari Sari A. Study of the relationship between nurses' work environment indices and their burnout aspects in TUMS teaching hospitals. Iran Occupational Health 2012; 9(3):39-51. 
4. Dashti S, Faradmal J, Soheili Zad M, Shahrabadi R, Salehiniya H. Survey of factors associated with burnout among health care staffs in Hamadan County in year 2012. Pajouhan Scientific Journal 2014; 13(1):1-8.

5. Ashoori J. Prediction nurse's job burnout based on social capital, perceived social support and organizational citizenship behavior. Pajouhan Scientific Journal 2017; 15(2):13-9.

6. Kowalski C, Ommen O, Driller E, Ernstmann N, Wirtz MA, Köhler T, et al. Burnout in nurses the relationship between social capital in hospitals and emotional exhaustion. J Clin Nurs 2010; 19(11-12):1654-63.

7. Sharafi H, Gholami $P$, Sadeghi S, Ghorbani M, Rezaei F. Job Stress and Related Factors among Staff of the Operation Room in Bandar Abbas. Iranian Journal of Rehabilitation Research in Nursing 2018; 4(2):29-34.

8. Vosoughi Niri A, Ruhollahi A, Mohmmad Hosein $H$. A survey of effect of job stress on general health and job performance on Air Traffic Controllers (ATC). Iran Occupational Health 2016; 13(1):47-57.

9. Wang W, Kong AW, Chair SY. Relationship between job stress level and coping strategies used by Hong Kong nurses working in an acute surgical unit. Appl Nurs Res 2011; 24(4):23843.

10. Cavalheiro AM, Moura Junior DF, Lopes AC. Stress in nurses working in intensive care units. Rev Lat Am Enfermagem 2008; 16(1):29-35.

11. Rothon C, Goodwin L, Stansfeld S. Family social support, community "social capital" and adolescents' mental health and educational outcomes: a longitudinal study in England. Soc Psychiatry Psychiatr Epidemiol 2012; 47(5):697709.

12. Boyas J, Wind LH, Kang SY. Exploring the relationship between employment-based social capital, job stress, burnout, and intent to leave among child protection workers: An age-based path analysis model. Child Youth Serv Rev 2012; 34(1):50-62.

13. Irandoost SF, Lebni JY, Soofizad G, Chaboksavar F, Khalili S, Mehedi N, Solhi M. The prevalence of burnout and its relationship with capital types among university staff in Tehran, Iran: A cross-sectional study. Heliyon 2021; 7(1):e06055.

14. Sepahvandi M, Movahedi $Y$, Azizi A, Lashani A, Mohammadzadigan $R$. The investigation relationship between dimensions of social capital with burnout nurses in Khorramabad academic hospitals. Journal of Nursing
Education 2014; 3(1):41-50.

15. Janssens $H$, Braeckman $L$, Vlerick $P$, Van de Ven B, De Clercq B, Clays E. The relation between social capital and burnout: a longitudinal study. Int Arch Occup Environ Health 2018; 91(8): 1001-9.

16. Leiter MP, Shaughnessy K. The Areas of Worklife Model of burnout: tests of mediation relationships. Ergonomia: An International Journal 2006; 28(4):327-41.

17. Griffin ML, Hogan NL, Lambert EG, Tucker-Gail KA, Baker DN. Job Involvement, Job Stress, Job Satisfaction, and Organizational Commitment and the Burnout of Correctional Staff. Crim Justice Behav 2010; 37(2):239-55.

18. Driller E, Ommen O, Kowalski C, Ernstmann N, Pfaff $\mathrm{H}$. The relationship between social capital in hospitals and emotional exhaustion in clinicians: a study in four German hospitals. Int J Soc Psychiatry 2011; 57(6):604-9.

19. Barabadi M, Golparvar M, Atashpoor H. The role of job demands, job resources, and burnout in the prediction of task performance. Knowledge \& Research in Applied Psychology 2015; 16(1):13-21.

20. Farahbod F, Goudarzvand Chegini M, Kouchakinejad Eramsadati L, Mohtasham-Amiri Z. The association between social capital and burnout in nurses of a trauma referral teaching hospital. Acta Med Iran 2015; 53(4):214-9.

21. Gächter M, Savage DA, Torgler B. The relationship between stress, strain and social capital. Policing 2011; 34(3):515-40.

22. Boyas J, Wind LH. Employment-based social capital, job stress, and employee burnout: $A$ public child welfare employee structural model. Child Youth Serv Rev 2010; 32(3):380-8.

23. Akram T, Qayyum A. An Analysis of the Relationship between Social Capital and Occupational Stress in Banking Industry of Pakistan. Pakistan Journal of Commerce and Social Sciences 2014; 8(1):112-33.

24. Lambert EG, Hogan NL, Jiang S. A Preliminary Examination of the Relationship between Organisational Structure and Emotional Burnout among Correctional Staff. The Howard Journal of Criminal Justice 2010; 49(2):125-46.

25. Shalani B, Abbariki A, Sadeghi S. Prediction of Job Stress Based on Psychological Capital and Job Performance in Nurses of Kermanshah Hospitals. Depiction of Health 2020; 10(4):2806. 